\title{
RITUALISED DUNG KICKING BY WHITE RHINO MALES AMPLIFIES OLFACTORY SIGNALS BUT REDUCES ODOUR DURATION
}

\author{
MARNEWECK $C^{1 *}$, JÜRGENS A², SHRADER AM ${ }^{1,3}$ \\ ${ }^{1}$ School of Life Sciences, University of KwaZulu-Natal, South Africa. \\ ${ }^{2}$ Chemical Plant Ecology, Technische Universität Darmstadt, Germany. \\ ${ }^{3}$ Mammal Research Institute, Department of Zoology and Entomology, University of Pretoria, South \\ Africa. \\ ${ }^{*}$ Current address: School of Biology and Environmental Sciences, University of Mpumalanga, South \\ Africa. \\ CM ORCID: 0000-0002-5064-1979 \\ AMS ORCID: 0000-0002-6451-6132
}

Acknowledgements: We thank Dr. Adam Shuttleworth for processing GC-MS samples and Chris Kelly (WildlifeACT Fund) for use of camera traps. 


\begin{abstract}
Many mammals enhance their olfactory signals visually by depositing them in conspicuous locations such as well-travelled paths. It is also possible to enhance the odour itself through behaviours aimed at modifying odour emission rates. White rhinos defecate in communal middens. While defecating, territorial males kick sharply with their back feet which disperses their dung. Despite being a ubiquitous trait of territorial male white rhinos, the reason behind this behaviour is unclear. We hypothesised that the purpose of dung kicking was for olfactory signal amplification (OSA) in terms of an increased emission of volatile compounds (i.e. increased signal strength). Using dung collected from nonterritorial adult males (because it is not possible to collect whole dung from territorial males), we show that the dispersal of male white rhino dung causes OSA by increasing the emission of hydrocarbon acids. The dung odour of territorial and non-territorial males differs only quantitatively, hence it is likely that the same emission patterns occur for territorial male dung odours following dung dispersal. The volatile compound indicating age of intact dung was toluene, but for dispersed dung it was acetophenone (similar to territorial male dung). Despite the benefits of OSA, dung dispersal carried a cost of decreased odour longevity. Thus, signal detectability is temporally reduced. However, territorial males likely counteract this by defecating in middens both before and during peak visitation times by other individuals (15:00-23:00). As a result, we suggest that dung kicking by territorial males amplifies signal strength, such that their dung odours are the most prominent and easily detectable by individuals visiting the middens. This would then better signal territorial ownership to both potential rivals and potential mates.
\end{abstract}

Key Words - Ceratotherium simum, dung dispersal, odour amplification. 


\section{INTRODUCTION}

Olfactory signals communicate a wide range of information including territory ownership, reproductive state, and group membership (Barja et al. 2005; Theis et al. 2012; Archunan and Rajagopal 2013). Information within these signals is transmitted via volatile organic compounds (VOCs) emitted from urine, faeces, and/or specialised glandular secretions (Archunan and Rajagopal 2013; Karthikeyan et al. 2013; Cross et al. 2014). As VOCs disperse from their source, their concentration decreases with increased distance. Therefore, the active space of an olfactory signal is the area around an odour source where the VOCs are at sufficient concentration to produce a behavioural reaction from a receiver (Elkinton and Cardé 1984). As the dispersal of olfactory signals is influenced by environmental factors, which can be seasonally driven, such as heat and wind (Bossert 1968; Alberts 1992; Nimmermark and Gustafsson 2005), a key challenge for animals using olfactory communication is to increase the likelihood that individuals will detect these signals (Gosling and Roberts 2001). One way this can be achieved is through visual enhancement. For example, individuals can increase detectability by depositing scent marks in heavily utilised areas. Wolves (Canis lupus) do this by leaving faecal marks on regularly used paths and crossroads (Barja et al. 2004). In addition, the specific location of scent marks can also provide key information. Elevated scent marks provide visual enhancement, but this also provides information on the depositor's body size and thus competitive ability (Alberts 1992; White et al. 2002; Sharpe 2015). Further, placing scent marks at elevated locations may also effect odour dispersal by increasing the active space (Gorman and Mills 1984; Alberts 1992). For example, black backed jackals (Canis mesomelas) defecate on top of rocks and large herbivore dung piles (Hayward and Hayward 2010) which increases the height, and therefore the active space, of their faecal marks. Consequently, strategic placement of scent marks can offer olfactory signal amplification (OSA) as well as visual enhancement.

Increasing the duration of an odour is another form of OSA. Lipids found in the urine marks of lions (Panthera leo) and tigers (Panthera tigris) slow down the release of VOCs and therefore increase longevity of the odour (Asa 1993; Andersen and Vulpius 1999; Burger et al. 2008). However, many species do not possess physiological mechanisms that regulate odour release, and thus rely on adjusting their behaviour to increase signal detection (e.g. strategic placement of scent marks). Although behavioural OSA has been suggested, studies investigating the effect of specific behaviours on odour release are limited. Moreover, herbivores in particular remain understudied in this regard. For instance, beira (Dorcatragus megalotis) (Giotto et al. 2008), black wildebeests (Connochaetes gnou) (Skinner and Chimimba 2005), dik-diks (Madoqua kirkii) (Tinley 1969), oribi (Ourebia ourebi) (Monfort and Monfort 1974), sable (Hippotragus niger) (Estes 1991), springboks (Antidorcas marsupialis) (Estes 1991), steenboks (Raphicerus campestris) (Walther 1990), suni (Neotragus moschatus) (Somers et al. 1990), and Thompsons gazelles (Eudorcas thomsonii) (Estes 1991) all perform ground scraping as part of their defecation sequence, but the reason for such behaviour is largely unknown. 
White rhino (Ceratotherium simum) olfactory signals are concentrated in communal middens (also called dung piles or latrines) by individuals of all ages and sex (Owen-Smith 1973), where age, sex, territorial and oestrous state are identifiable via dung odours (Marneweck et al. 2017a). These middens are located at strategic locations including territory boundaries, well-travelled rhino paths, and next to water sources (Owen-Smith 1973), which increases encounter probability. The primary function of middens is for territorial males to advertise territory ownership (male-male communication) and find reproductive females (female-male communication) (Marneweck et al. 2018). However, secondary functions likely include non-territorial males locating reproductive females for sneaky copulations, females to assess male quality (male-female communication), and potential challengers to assess both the territorial male and territory quality (Marneweck et al. 2018).

At a fine scale, individual white rhinos defecate in specific locations within a midden. Territorial males defecate in the centre, while non-territorial males, adult females, and younger animals primarily defecate around the edge (Owen-Smith 1973; Marneweck et al. 2018). This spatial distribution of dung may increase the detectability of the signals from these different individuals (Marneweck et al. 2018). Yet, within these middens, territorial males are the only individuals to scatter their dung, which they do with backward kicking motions of their hind feet (Owen-Smith 1971) (Supplementary video). To date, it is unclear why they do this. As one of the main functions of middens is communication from territorial males (i.e. male-male and male-female communication; Marneweck et al. (2018)), it is possible that these males kick their dung to enhance their olfactory signals (i.e. OSA). To explore this, we tested whether the increase in dung surface area caused by kicking resulted in an increase in VOC emission, and thus facilitated OSA. However, odour amplification could lead to a decrease in odour longevity. Plants produce VOCs (Lerdau et al. 1997), so their VOC emission is limitless. However, odour sources such as scent marks do not produce VOCs, rather, they emit them as the result of the organic matter and bacterial breakdown (Archie and Theis 2011). This results in VOC emission being finite. Therefore, if an individual were to increase the emission of their scent mark via OSA, the overall longevity would likely be reduced. If this is the case, then dung kicking by territorial males could constitute a strategy of increasing VOC emission at the expense of odour duration. To counteract the reduced longevity, territorial males could adjust their behaviour such that they deposit dung at optimal times to ensure detection before odour depletion (i.e. during times of high midden use by other individuals). To investigate this, we tested the following hypotheses: (1) the dispersal of male dung will cause an increase in VOC emission, (2) the increase in VOC emission will ultimately decrease odour longevity, and (3) territorial males will defecate during periods of high visitation by other individuals to increase olfactory signal detectability.

\section{METHODS AND MATERIALS}

Collection of Dung Odours. We conducted this study between May and August 2014 (i.e. dry season) in the $896 \mathrm{~km}^{2}$ Hluhluwe-iMfolozi Park, KwaZulu-Natal, South Africa. Here, we collected a fresh $(<5$ 
minutes) dung sample (one dung bolus) from a total of 19 different non-territorial (subordinate) adult male white rhinos. We identified individuals by variations in horn shape, skin folds, and other distinguishing characteristics, with adults defined as individuals $>7$ years of age (Hillman-Smith et al. 1986). There are no physical differences between territorial and non-territorial males (Owen-Smith 1971; Owen-Smith 1973) and as such, we identified territorial status from behaviour. We defined territorial males as adult males performing territorial-specific behaviours of dung kicking and spray urination, and non-territorial males as adult males not performing these territorial-specific behaviours (Owen-Smith 1971; Owen-Smith 1973).

We used dung from non-territorial adult males as a surrogate for territorial males, as it was not possible to obtain intact (i.e. whole and un-kicked) dung boluses from territorial males (see Fig. 1). This is because territorial males kick before, during, and after defecating, which breaks up the boluses (Owen-Smith, 1973). We felt confident in using non-territorial dung as a surrogate because the VOCs emitted from territorial and non-territorial male dung differ only quantitatively, with territorial males emitting higher proportions of hydrocarbon acids (Marneweck et al. 2017a). This is likely due to higher concentrations of faecal testosterone found in territorial male dung (Rachlow and Berkeley 1998). Specifically, the proportion of acids emitted is $69 \%$ higher in territorial dung compared to what is emitted from non-territorial dung (Marneweck et al. unpublished data). Therefore, we expected the same pattern of emission in territorial dung odours, just on a larger scale. Specifically, we would expect the dispersal of dung to cause a larger increase in acid emission from territorial dung compared to that emitted from dispersed non-territorial dung. Moreover, the classification algorithm used in Marneweck et al. (2017a) had fairly low success in identifying the territorial state of males from dung odours, highlighting the similarities. Consequently, we are confident that non-territorial male dung provides a suitable surrogate with which to explore OSA patterns of territorial male dung.

To collect dung samples, we followed individual white rhinos on foot until they defecated. To ensure that the rhinos were unaware of our presence, and thus not disturb natural behaviour, we remained downwind and followed individuals at a distance of $\sim 50 \mathrm{~m}$. Moreover, once a rhino had defecated, we did not approach the midden until the individual had moved $>50 \mathrm{~m}$ away. After they had defecated, we removed a fresh bolus from the midden and collected an odour sample using headspace extraction (Amirav and Dagan 1997). We collected an odour sample by collecting the air for 25 minutes from dung enclosed in a polyacetate bag using a micro-air sampler (Supelco PAS-500) with a realized flow rate of $150 \mathrm{ml} / \mathrm{min}$. VOCs emitted from the dung were captured in a small thermodesorption trap filled with $1 \mathrm{mg}$ of Tenax ${ }^{\circledR}$ and $1 \mathrm{mg}$ of Carbotrap ${ }^{\circledR}$. We collected an initial odour sample $(<5 \mathrm{~min}$ after defecation, representing dung at 0 hours) in the field and then removed the bolus from the midden to ensure that the odour sample was restricted to the specific individual. We then relocated the bolus to the research camp where we collected subsequent odour samples at 6, 12, 24, and 48 hours from time of defecation. We chose these times based on Marneweck et al. (2017a) and Marneweck et al. (2017b), where changes occur rapidly during the first 12 hours and persist for approximately 48 hours. In between 
(a)

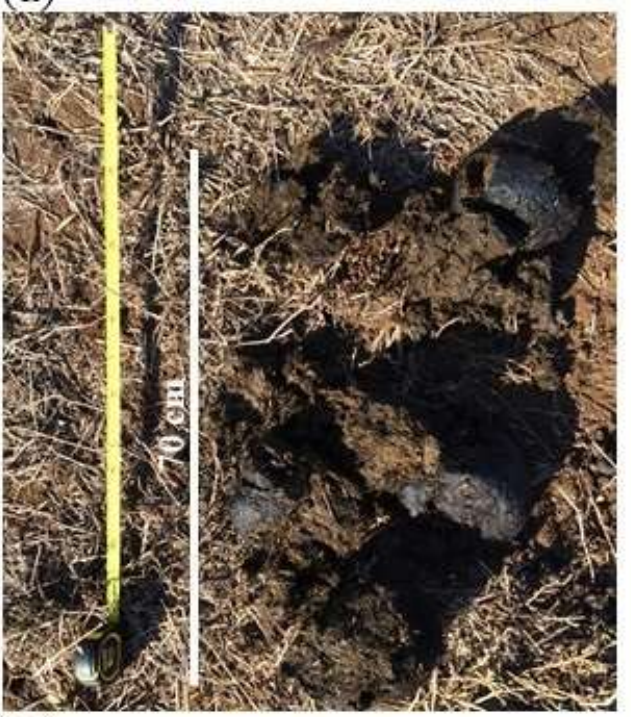

(c)

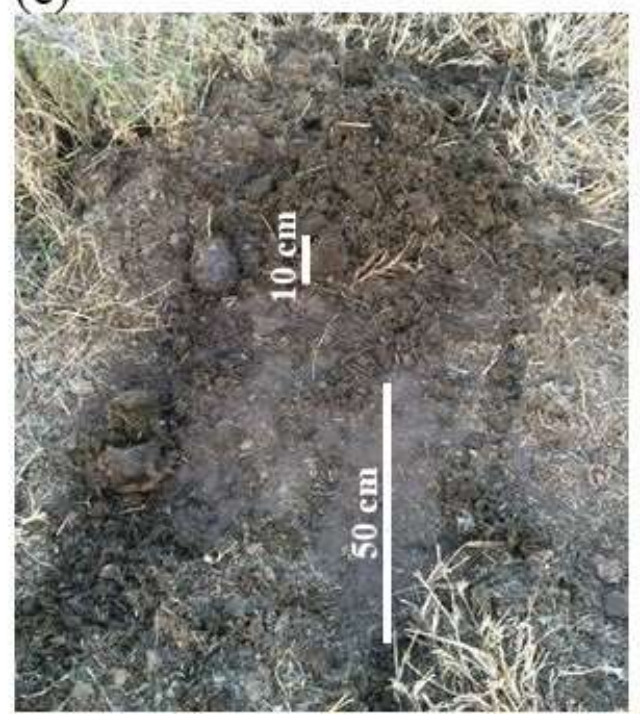

(b)

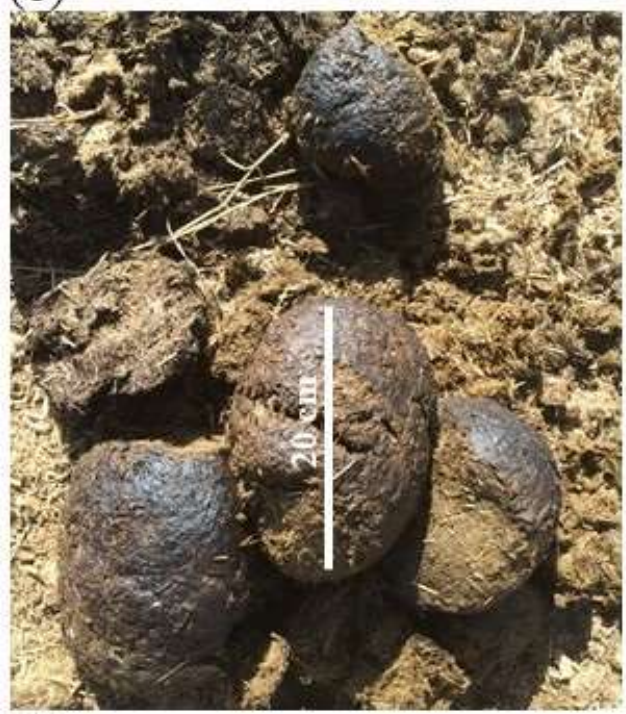

(d)

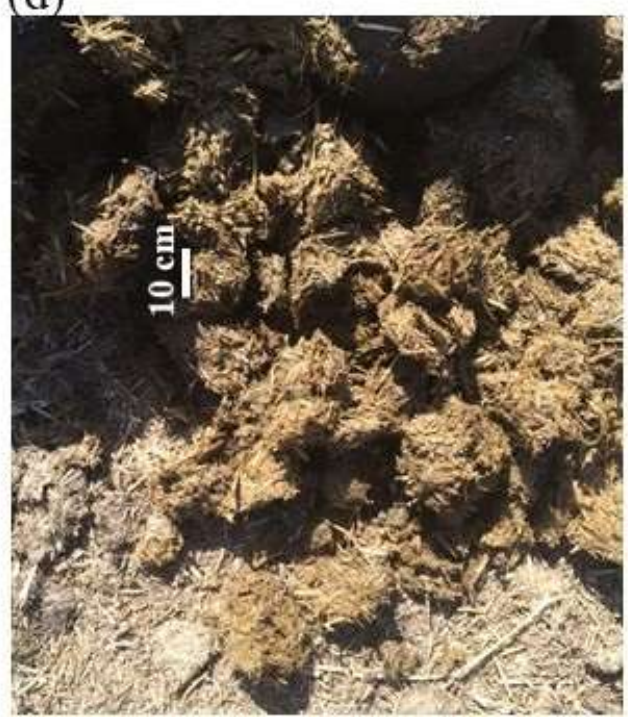

Figure 1. Photos (a) and (b) represent a non-territorial male dung pile, (c) a territorial male dung pile with noted scrape marks from kicking, and (d) an artificially dispersed non-territorial male dung pile.

sampling intervals, we left the dung outside on natural substrate (short grass), unprotected, to allow natural degradation to occur. We left dung either as one solid bolus or as scattered pieces (see below) during this time. After 48 hours, we returned dung to the environment and stored the thermodesorption traps for later laboratory analysis.

To determine if breaking up of the dung bolus resulted in OSA, we first collected odour samples from ten intact boluses. To mimic the kicking action of territorial males, we then broke up the remaining boluses $(n=9)$ into similar sized pieces to what is found in the wild $(3 \times 3 \times 6 \mathrm{~cm}-5 \times 5 \times$ $10 \mathrm{~cm}$; Marneweck pers. obs., Fig. 1). We did this by hand, using a polyacetate bag as a glove to prevent any odour contamination. Once the bolus was broken apart, we collected odour samples from the combined separated pieces of the bolus. In total, we collected 92 odour samples; intact boluses $n=49$ 
(10 at 0 hours, 10 at 6 hours, 10 at 12 hours, 10 at 24 hours, and 9 at 48 hours), dispersed boluses $n=43$ ( 9 at 0 hours, 9 at 6 hours, 9 at 12 hours, 9 at 24 hours, and 7 at 48 hours). Some dung samples were lost to the environment (due to removal by birds, dung beetles, and wind) and as a result, some of the samples sizes are lower at 48 hours from defecation.

Dung Odour Analysis. We carried out gas chromatography-mass spectrometry (GC-MS) analysis of the odour samples on a Bruker $450 \mathrm{GC}$ with a $30 \mathrm{~m}$ x $0.25 \mathrm{~mm}$ internal diameter Varian VF-5ms column, connected to a Varian VF-1ms column coupled to a Bruker 300 quadrupole mass spectrometer in electron-impact ionization mode at $70 \mathrm{eV}$. Thermodesorption traps were placed in a Varian 1079 injector equipped with a chromatoprobe thermal desorption device. We identified VOCs using Varian Workstation software with the NIST 2011 mass spectral library (NIST/EPA/NIH Mass Spectral Library, data version: NIST 2011; MS search software version $2.0 \mathrm{~d}$ ). We verified the identification of VOCs with retention times of authentic standards and published Kovats indices wherever possible (Supplementary material).

Quantification of the VOC emission rates were carried out using injections of standardised volumes of a set of commercially (Sigma-Aldrich) available standards. One calibration compound per VOC functional group was injected as a placeholder for all VOCs in the group. We selected six synthetic standards (acetic acid, benzaldehyde, limonene, methyl salicylate, (Z)-hex-3-en-1-ol, (E)- $\beta$ caryophyllene) that covered a range of chemical structures found in the dung odour samples, e.g. acetic acid was selected as a standard for hydrocarbon acids, limonene was injected as a standard for monoterpenes, (E)- $\beta$-caryophyllene acted as the placeholder for all sesquiterpenes. Each compound was injected three times, following the same methods as for the dung samples. The peak areas in the chromatograms were averaged per injected standard, resulting in a conversion factor per VOC functional group. All VOCs in the functional group were subsequently standardised with this conversion factor. Finally, all samples were multiplied by the factor 2.4 to convert the emission rates in the sampling time of $25 \mathrm{~min}$ to the emission rate per hour. In the following, all emission rates are scaled to mg per hour.

Collection of Behavioural Data. We collected behavioural data between April and September 2015 (i.e. dry season) to correlate with the odour data collection period. We set up motion-triggered video recording camera traps at ten middens, each frequented by a different resident territorial male (identified via differences in horn shape and size). An average territory is $1.65 \mathrm{~km}^{2}$ (Owen-Smith 1975), therefore, focal middens were separated by at least $2 \mathrm{~km}$ to help ensure separation. Further, video recordings confirmed that the middens were utilised by different territorial males. To record behavioural data, we used infrared camera traps (either a Cuddeback Black Flash ${ }^{\circledR}$ E3 or Cuddeback Attack Black Flash ${ }^{\circledR}$ 1194 model). We used these cameras as they do not emit visible light or have a flash, creating minimal disturbance at the midden and therefore allowing us to capture natural behaviour. We placed cameras 
approximately 3 metres from the edge of the midden to allow for sufficient field of view. We programmed the cameras to record 30-second videos at each trigger with a 1-second delay before becoming active again. From this, we created a profile for each adult white rhino so that we could record individual visitation and defecation times.

From the video footage, we recorded data on all adults (identified as individuals $>7$ years based on body size and horn development; Hillman-Smith et al. (1986), identified territorial males as adult males performing territorial behaviours (i.e. dung kicking, spray urinating), and non-territorial as adult males not performing these behaviours (Owen-Smith 1971; Owen-Smith 1973). Although the oestrous state of female white rhinos can be determined by observing the behaviours of territorial males (i.e. following, mounting etc. Owen-Smith (1973)), we were unable to record these behaviours on the cameras and thus unable to identify female oestrous state. As a result, we grouped all adult females together for analysis.

Statistical Analysis. As absolute concentration is subject to variability across samples, we used relative abundance of a VOC within a sample (i.e. proportion) for statistical analysis. To assess if the odours of intact and dispersed dung were different over the 48-hour sampling period, we conducted a permANOVA based on Bray-Curtis similarities of square-root transformed proportions with posthoc pairwise comparisons.

To investigate if time (i.e. hours from defecation) or treatment (i.e. intact or dispersed) had an effect on the contribution of each VOC functional group to the odour, we created five candidate linear mixed-effects models. We set the contribution of each VOC functional group as the response variable, time and treatment, plus interactions between time, treatment, and VOC functional group as explanatory variables. We controlled for individual rhino identity as a random factor in all candidate models. We did not include VOC functional group alone because it is uninformative as each functional group contribution varies considerably (Marneweck et al. 2017b).

Using a random forest classification algorithm, we interpreted the best predictors (i.e. VOCs) of dung age using the metric mean decrease in accuracy (MDA). The MDA is the increase in the percentage of times the outcome is misclassified when the variable is randomised. A higher MDA means less misclassification, and thus greater accuracy, and ultimately indicates higher importance to the classification.

To investigate if time or treatment had an effect on the number of VOCs emitted from nonterritorial male dung (a surrogate for VOC emission), we created three candidate linear mixed-effects models. We set the number of VOCs emitted as the response variable, time and treatment, plus their interaction, as explanatory variables, and controlled for individual rhino identity as a random factor.

To investigate if time or treatment had an effect on the absolute emission of VOCs from nonterritorial male dung, we created a further three candidate linear mixed-effects models. We set the log 
of the absolute emission as the response variable, time and treatment, plus their interaction, as explanatory variables, and controlled for individual rhino identity as a random factor.

We recorded the time of each visit and defecation for all adults and categorised them into one of six four-hour time periods (11:00-14:59, 15:00-18:59, 19:00-22:59, 23:00-02:59, 03:00-06:59 or 07:00-10:59). These time periods were based on the active periods recorded by Owen-Smith (1973), where white rhinos are often found resting during the heat of the day. We calculated the number of visits and defecations per individual during each time period as a proportion of their total number of visit and defecations. To assess the factors affecting the time of midden visit or defecation from individuals of different adult state (i.e. territorial male, non-territorial male, and female) we created three candidate linear mixed-effects models. We set the proportion of visits per time period as the response variable, state and time period, plus their interaction, as explanatory variables, and controlled for individual rhino identity as a random factor. We repeated this analysis for the proportion of defecations per time period.

We assessed collinearity between independent explanatory variables prior to analysis using variance inflation factors (VIF) and Spearman rank correlation tests, ensuring that all variables had VIF values below 2 in the final statistical models. To identify the best model(s), we used model selection based on Akaike Information Criterion ( $\mathrm{AIC} c$ ), where $\triangle \mathrm{AIC} c \leq 2$ indicates most important predictors (Burnham and Anderson 1998). We performed all statistical analyses and created all figures in RStudio v 1.0.136 (Team 2016) for Windows, using functions in the packages nlme (Pinheiro et al. 2015), MuMIn (Bartoń 2013), randomForest (Liaw and Wiener 2012), and vegan (Oksanen et al. 2015).

\section{RESULTS}

\section{Odour}

An interaction between time (i.e. hours from defecation) and treatment (i.e. intact or dispersed) had a significant effect on overall dung odour $\left(\mathrm{F}_{4}=2.142, \mathrm{P}=0.002\right)$. At $0,6,12$, and 24 hours from defecation, the odour of dispersed dung was significantly different to the odour of intact dung ( 0 hours: $\mathrm{t}=2.1244, \mathrm{P}=0.001$, Fig. 2a; 6 hours: $\mathrm{t}=1.9496, \mathrm{P}=0.001$, Fig. $2 \mathrm{~b} ; 12$ hours: $\mathrm{t}=1.8279, \mathrm{P}=0.008$, Fig. 2c; 24 hours: $t=2.4154, P=0.001$; Fig. $2 d$ ). However, at 48 hours from defecation, the odour of dispersed and intact dung was similar $(\mathrm{t}=1.4941, \mathrm{P}=0.059$, Fig. 2e $)$. 

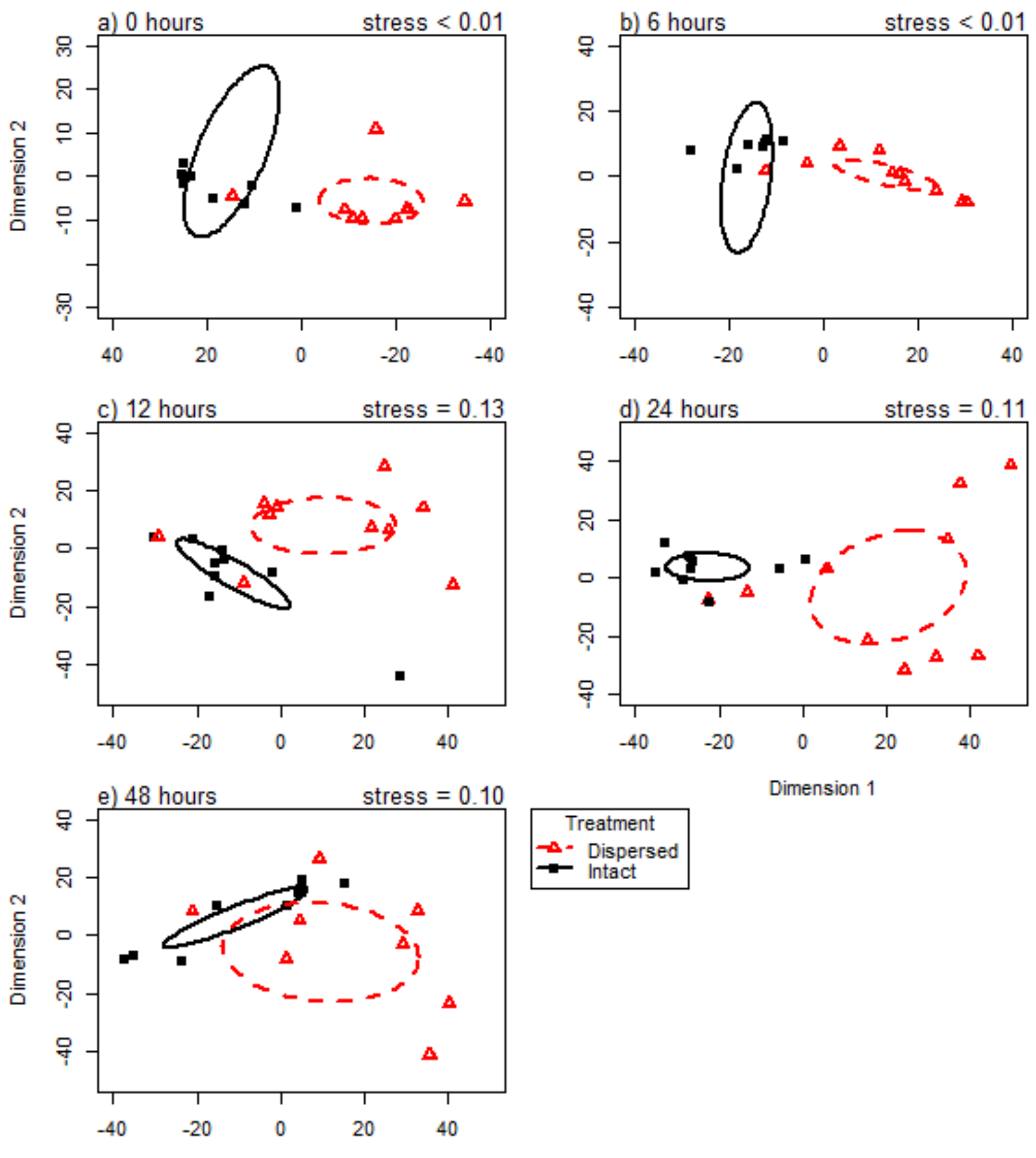

Dimension 1

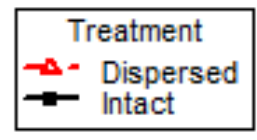

Dimension 1

Figure 2. Multidimensional scaling (MDS) plot based on Bray-Curtis similarities of the variation of VOCs emitted from male dung, intact and dispersed, at a) 0 hours, b) 6 hours, c) 12 hours, d) 24 hours, and e) 48 hours from defecation. Each point represents one dung sample odour. Encompassing circles represent $95 \%$ confidence intervals.

An interaction between VOC functional group and treatment was the most important predictor of VOC functional group contribution to dung odour (Table 1), explaining almost all of the variation. Dispersal caused an increase in acids and benzenoids, and a decrease in monoterpenes (Fig. 3). The 
most important VOCs for indicating the age of intact and dispersed dung were the benzenoids toluene (Fig. 4a) and acetophenone (Fig. 4b), respectively.

Table 1. The five candidate models used to investigate factors affecting VOC contribution to dung odour. Top model is indicated in bold, where $\triangle \mathrm{AIC} c \leq 2$.

\begin{tabular}{lllllll}
\hline Rank & Model & $\boldsymbol{d f}$ & loglikelihood & AIC $\boldsymbol{~}$ & $\Delta$ AIC $\boldsymbol{~}$ & $\boldsymbol{w}_{\mathbf{i}}$ \\
\hline $\mathbf{1}$ & Group:Treatment & $\mathbf{2 8}$ & $\mathbf{1 2 8 2 . 7 6 5}$ & $\mathbf{- 2 5 0 8 . 6 2 4}$ & $\mathbf{0 . 0 0 0}$ & $\mathbf{0 . 9 9 9}$ \\
2 & Group:Time & 67 & 1281.831 & -2424.462 & 84.162 & $>0.001$ \\
3 & Treatment & 4 & 914.045 & -1820.068 & 688.556 & $>0.001$ \\
4 & Time & 7 & 903.024 & -1791.987 & 716.637 & $>0.001$ \\
5 & Time:Treatment & 12 & 887.133 & -1750.093 & 758.531 & $>0.001$ \\
\hline
\end{tabular}

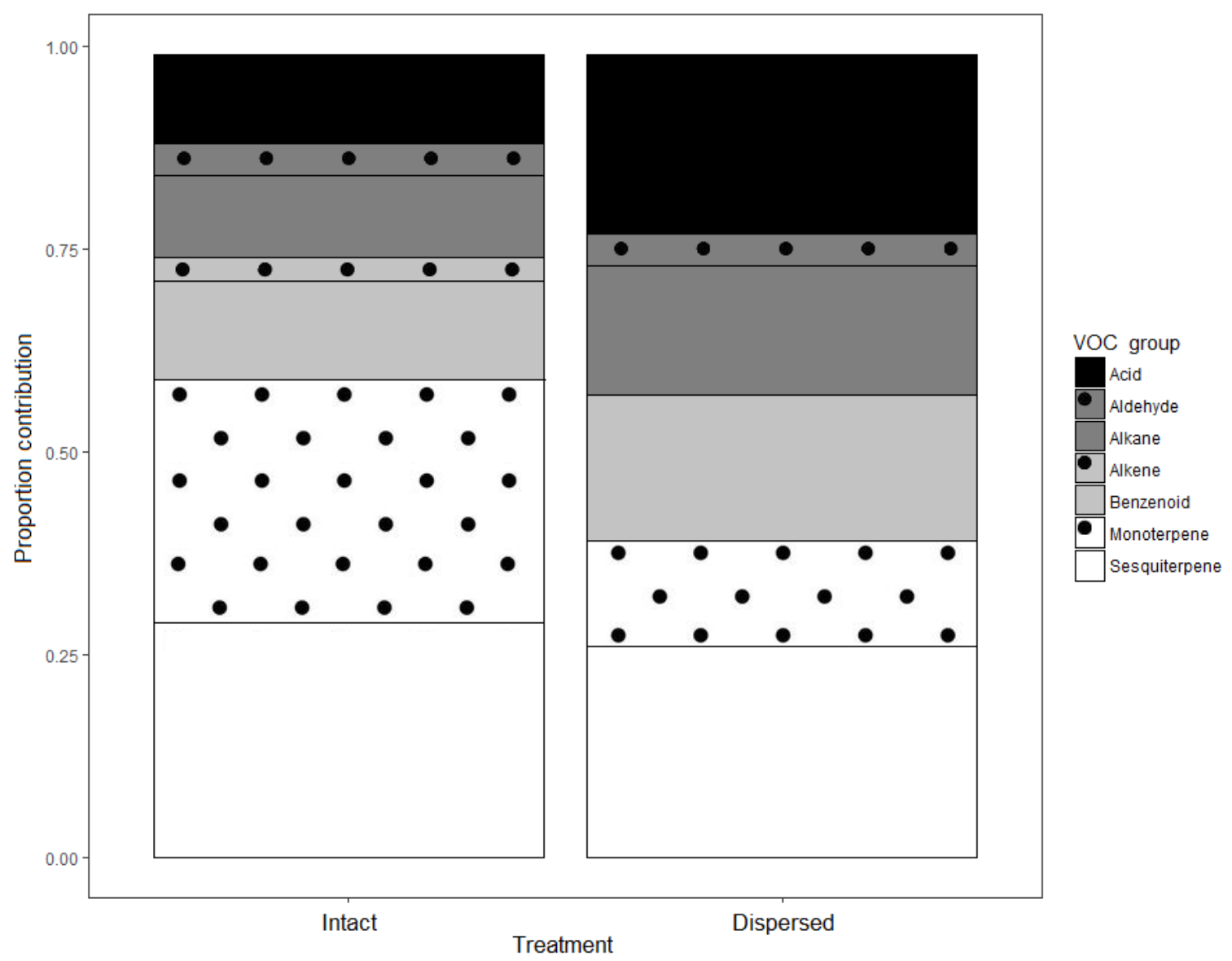

Figure 3. The composition of odour from intact and dispersed non-territorial male dung. 

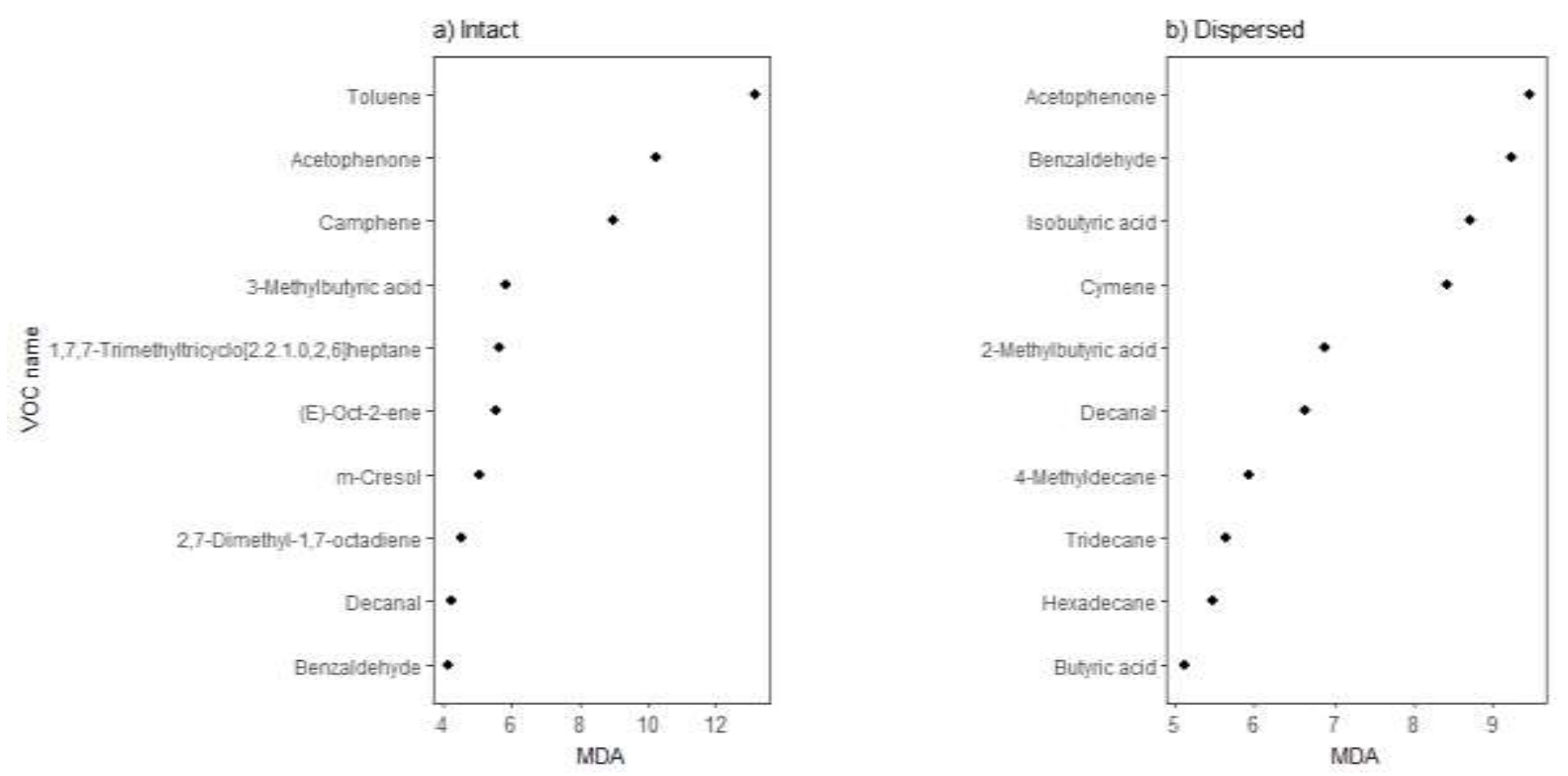

Figure 4. The importance of volatile organic compounds (VOCs) for distinguishing the age of dung when a) intact and b) dispersed. Importance was based on mean decrease in accuracy (MDA). Only the top ten compounds are presented in the figure.

An interaction between time and treatment was the most important predictor for the number of VOCs emitted from non-territorial dung (Table 2), explaining almost all of the variation. The dispersal of dung caused an increase in the number of VOCs emitted at 0 and 24 hours, had no effect between 612 hours, and caused a decrease in the number of VOCs emitted at 48 hours (Fig. 5).

Table 2. The three candidate models used to investigate factors affecting the number of VOCs emitted. Top model is indicated in bold, where $\triangle \mathrm{AIC} c \leq 2$.

\begin{tabular}{lllllll}
\hline Rank & Model & $\boldsymbol{d} \boldsymbol{f}$ & loglikelihood & AIC $\boldsymbol{c}$ & $\Delta \mathrm{AIC} \boldsymbol{c}$ & $\boldsymbol{w}_{\mathrm{i}}$ \\
\hline $\mathbf{1}$ & Time:Treatment & $\mathbf{1 2}$ & $\mathbf{- 2 9 3 . 3 7 0}$ & $\mathbf{6 1 4 . 6 8 9}$ & $\mathbf{0 . 0 0 0}$ & $\mathbf{0 . 9 9 9}$ \\
2 & Time & 7 & -307.315 & 629.962 & 15.274 & $>0.001$ \\
3 & Treatment & 4 & -335.337 & 679.133 & 64.445 & $>0.001$ \\
\hline
\end{tabular}




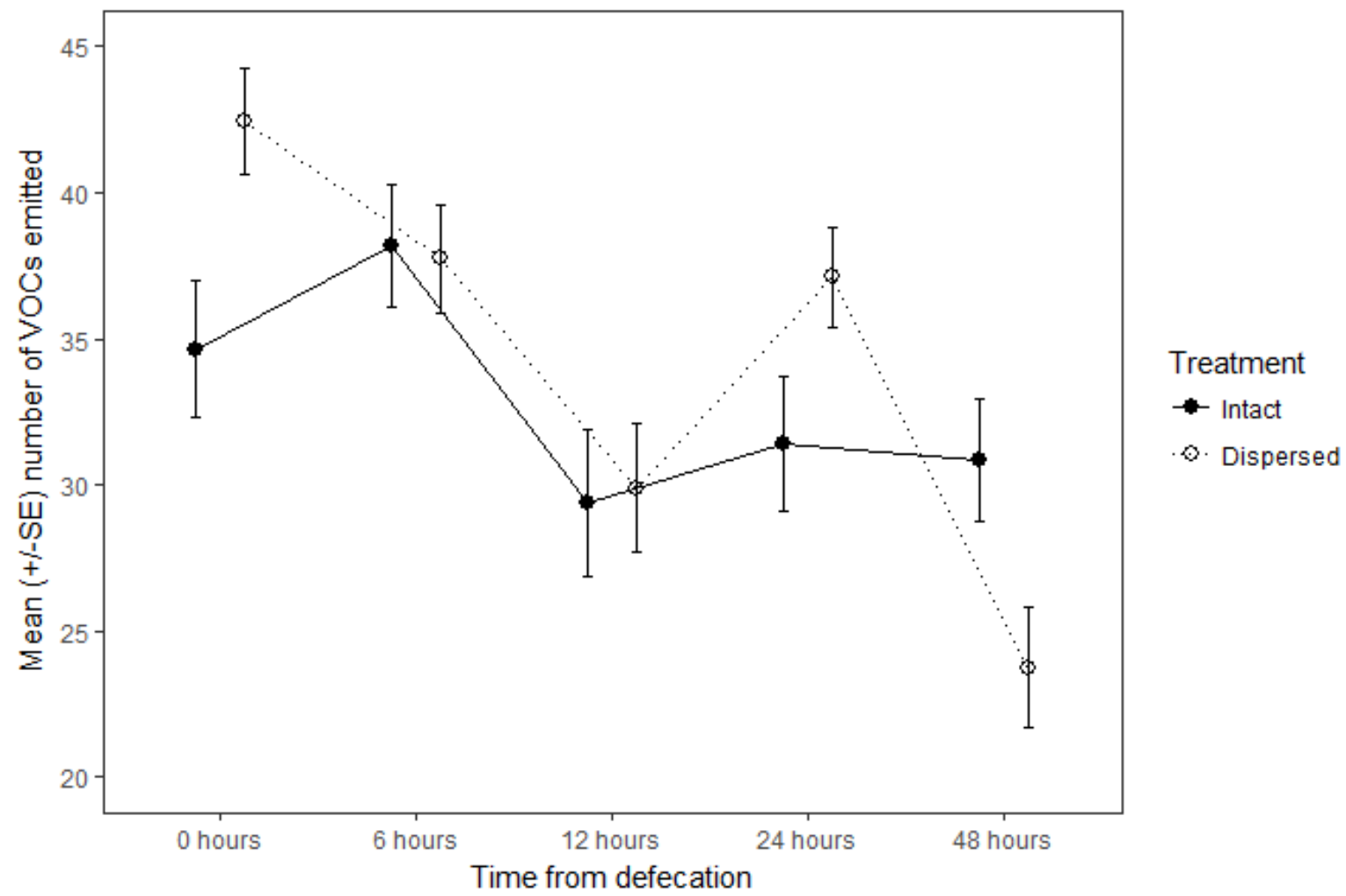

Figure 5. The mean number of VOCs emitted from non-territorial male dung, intact and dispersed, over 48 hours after defecation.

Although the mean absolute VOC emission from non-territorial dung was higher from dispersed dung compared to intact dung directly after defecation $(19.8 \pm 35.5$ and $13.4 \pm 20.7 \mathrm{mg} /$ hour, respectively; Fig. 6), and lower from dispersed dung for later periods, treatment did not affect absolute emission due to high variation (Table 3; Fig. 6). Time was the most important predictor for the absolute emission of VOCs from non-territorial dung (Table 3), explaining almost all of the variation, where absolute emission decreased over time (Fig. 6).

Table 3. The three candidate models used to investigate factors affecting the absolute emission rate of VOCs. Top model is indicated in bold, where $\triangle \mathrm{AIC} c \leq 2$.

\begin{tabular}{lllllll}
\hline Rank & Model & $\boldsymbol{d} \boldsymbol{f}$ & loglikelihood & AIC $\boldsymbol{c}$ & $\Delta$ AIC $\boldsymbol{c}$ & $\boldsymbol{w}_{\mathbf{i}}$ \\
\hline $\mathbf{1}$ & Time & $\mathbf{4}$ & $\mathbf{- 1 2 7 . 1 1 5}$ & $\mathbf{2 6 2 . 5 2 8}$ & $\mathbf{0 . 0 0 0}$ & $\mathbf{0 . 9 9 9}$ \\
2 & Time:Treatment & 6 & -131.729 & 276.095 & 13.567 & $>0.001$ \\
3 & Treatment & 4 & -137.769 & 283.837 & 21.308 & $>0.001$ \\
\hline
\end{tabular}




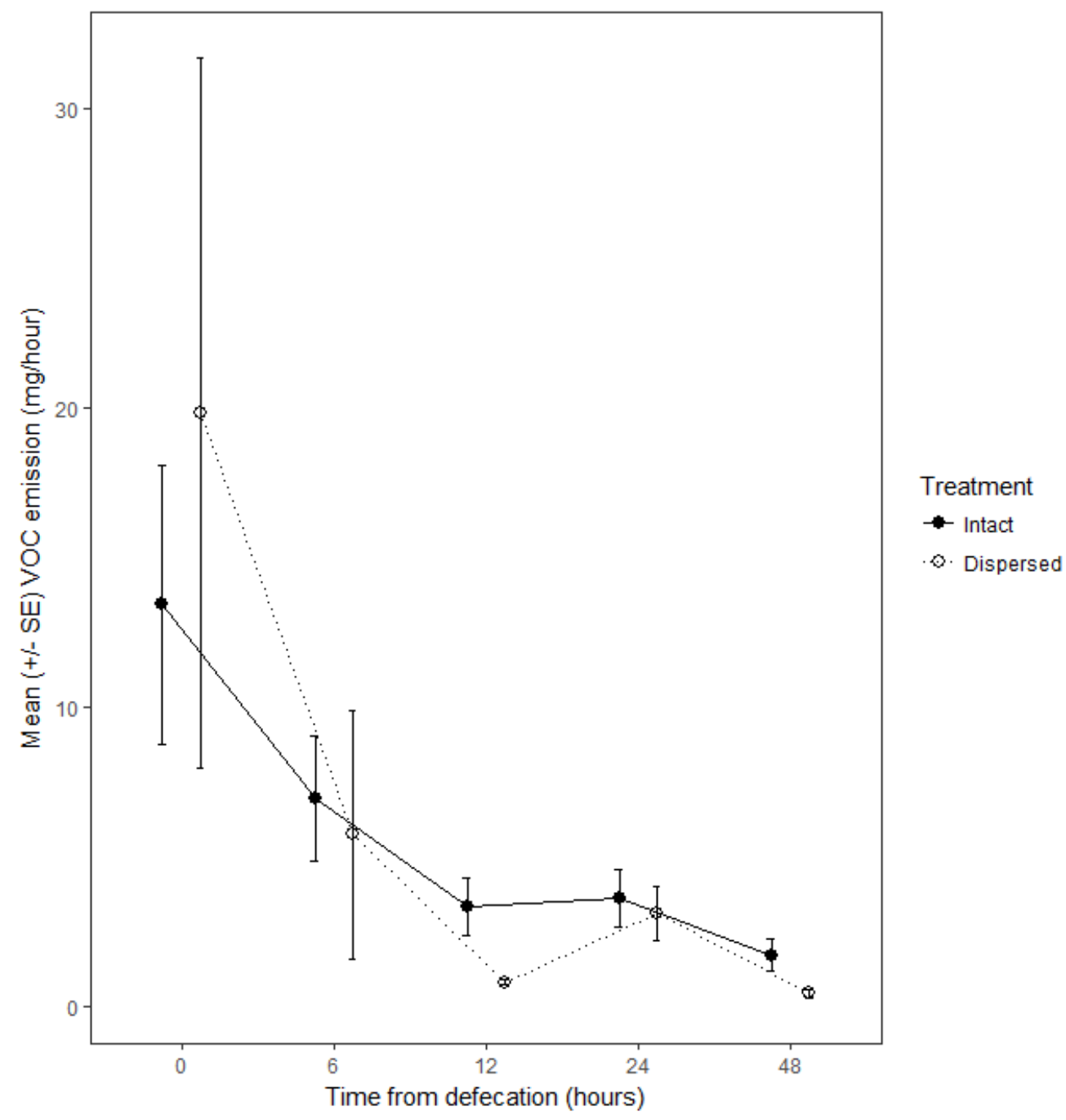

Figure 6. Mean absolute emission of volatile compounds from non-territorial male white hino dung both intact and dispersed.

\section{Behaviour}

An interaction between adult state (i.e. territorial male, non-territorial male, or female) and time was the most important predictor of both midden visit and defecation (Table 4), explaining almost all of the variation. Females visited middens more often during 15:00-18:59 and less often during 23:00-02:59 compared to both territorial and non-territorial males (Fig. 7a). Territorial males visited more often during 11:00-14:59 and 23:00-02:59 compared to non-territorial males and females (Fig. 7a). When defecating, territorial males defecated more often than non-territorial males and females during 11:0014:59 and 19:00-22:59. 

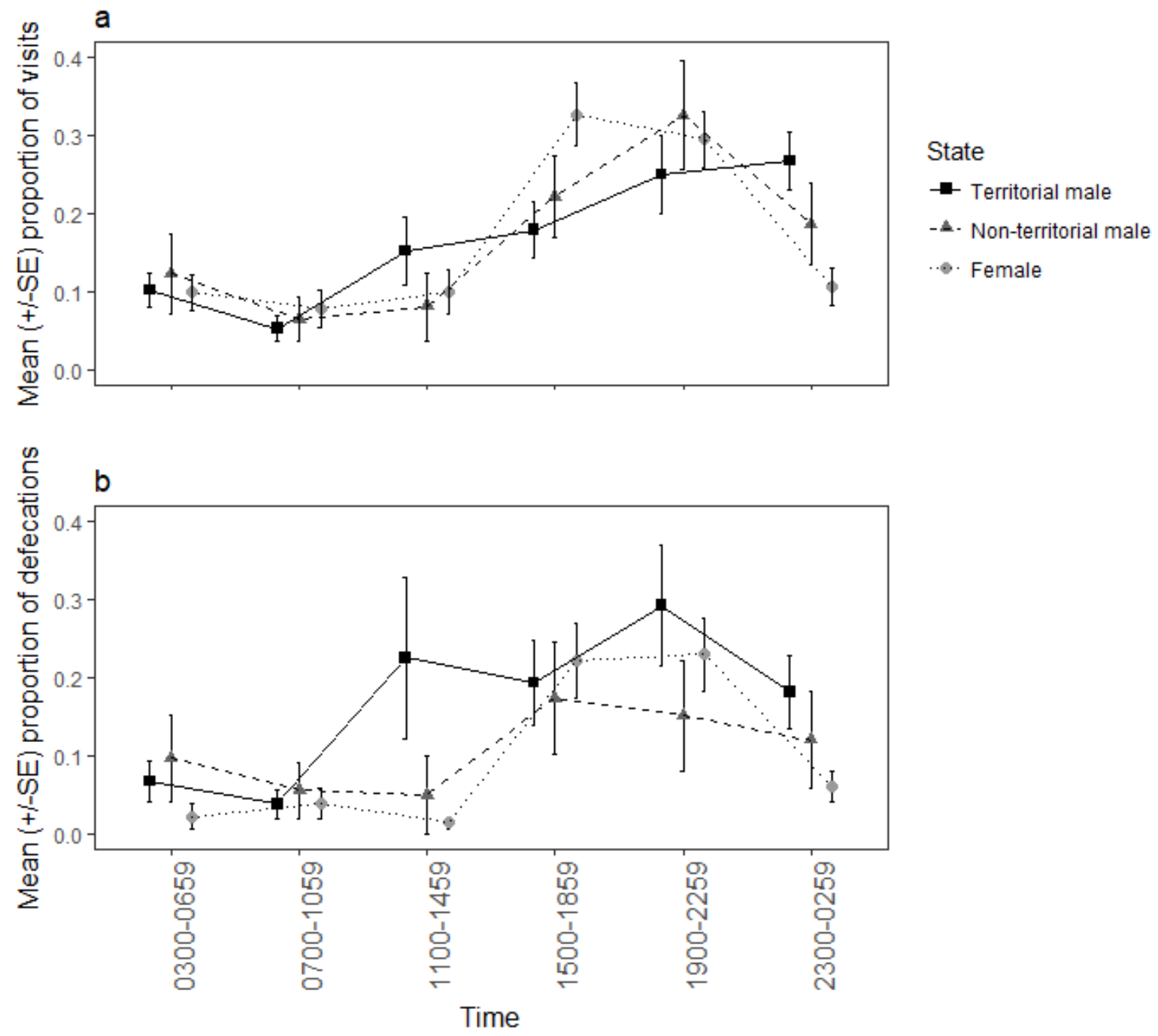

Figure 7. Mean proportion of midden (a) visits and (b) defecations by adults per time period.

Table 4. The six candidate models used to investigate factors affecting the visitation and defecation time of adult white rhinos. Top models are indicated in bold, where $\Delta \mathrm{AIC} c \leq 2$.

\begin{tabular}{lllllll}
\hline Rank & Model & $\boldsymbol{d} \boldsymbol{f}$ & loglikelihood & AIC $\boldsymbol{c}$ & $\Delta \mathrm{AIC} \boldsymbol{c}$ & $\boldsymbol{w}_{\mathrm{i}}$ \\
\hline \multicolumn{2}{l}{ Visitation } \\
$\mathbf{1}$ & State:Time & $\mathbf{2 0}$ & $\mathbf{- 1 4 0 3 . 9 7 6}$ & $\mathbf{2 8 4 9 . 4 6 5}$ & $\mathbf{0 . 0 0 0}$ & $\mathbf{0 . 9 9 8}$ \\
2 & Time & 8 & -1423.049 & 2862.351 & 12.886 & 0.002 \\
3 & State & 5 & -1466.128 & 2942.361 & 92.896 & $>0.001$ \\
\multicolumn{2}{l}{ Defecation } & & & & & \\
$\mathbf{1}$ & State:Time & $\mathbf{2 0}$ & $\mathbf{- 1 3 9 5 . 5 4 7}$ & $\mathbf{2 8 3 2 . 6 0 7}$ & $\mathbf{0 . 0 0 0}$ & $\mathbf{0 . 9 9 9}$ \\
2 & Time & 8 & -1418.394 & 2853.042 & 20.435 & $>0.001$ \\
3 & State & 5 & -1434.415 & 2878.936 & 46.328 & $>0.001$ \\
\hline
\end{tabular}




\section{DISCUSSION}

Olfactory signal amplification (OSA) increases signal detectability by either increasing the VOC emission (signal strength) or extending VOC emission (signal longevity) (Alberts 1992; Hayward and Hayward 2010; Piñeiro and Barja 2012). When defecating in communal middens, territorial male white rhinos are the only individuals that kick their dung (Owen-Smith 1973). It is possible that by doing this, these males amplify the olfactory signals released from their dung. Using non-territorial male dung as a surrogate, due to its similar VOC profile to territorial male dung coupled with the difficulty in obtaining un-kicked territorial male dung, we found that dispersal of the dung increased VOC emission (signal strength), but reduced signal duration (signal longevity). We found that the mean absolute emission rate of dispersed dung directly after defecation was higher than that of intact dung. For later time periods we found that dispersed dung had lower absolute emission rates than intact dung. However, these differences were not significant. The interpretation of absolute emission rates, as an indicator for signal intensity, is difficult for two reasons. Firstly, not all VOCs may play a role as an olfactory signal. Secondly, since there are no data on the olfactory sensitivity of white rhinos, we do not know at which threshold levels the animals start, or cease, to respond. A behavioural effect might be linked to a certain combination of compounds that together reach a given threshold level. Furthermore, it is likely that a reduction in emission strength does not affect signal detectability as territorial males defecated in middens before peak visitation times of other individuals.

Factors affecting the volatility of a VOC include its molecular weight and vapour pressure (Stoddart 1976). Further, a key factor determining VOC emission is the surface area from which the VOCs are emitted (Alberts 1992). In this study, hydrocarbon acids were larger contributors to the odour when the dung was dispersed, compared to when the bolus remained intact. These compounds have low molecular weight and high vapour pressure, making them susceptible to emission. Moreover, these VOCs are associated with territory ownership in white rhinos, where territorial male dung emits higher proportions of hydrocarbon acids than non-territorial male dung (Marneweck et al. 2017a). With the predicted pattern of $69 \%$ larger proportion acid emission for territorial male dung, this suggests that the hydrocarbon acids would be even larger contributors to territorial male odour and potentially dominate the odour after dung dispersal. As these VOCs are important for signalling territorial status, and their increased emission means quicker depletion, we would expect that the odour of territorial signals would be very strong, but the longevity even further reduced as a result of dung kicking. As increased testosterone levels are associated with greater competitive ability (Zielinski and Vandenbergh 1993), dispersal of the dung could create a signal of a larger and more competitive male, which has reproductive and intimidation benefits for females and non-territorial males respectively.

Acetophenone is the most important VOC for indicating the age of territorial male dung during the dry season (Marneweck et al. 2017b). Here, we identified a change in the most important VOC predictor for dung age of non-territorial male during the dry season. When intact, toluene is the most important VOC, as described in Marneweck et al. (2017b). However, when dispersed, acetophenone is 
the most important VOC. Thus, dispersal causes changes leading to odour similar to that from territorial male dung. Toluene is a benzenoid compound, and benzenoids are common VOCs emitted from plants and thus represent undigested plant material in white rhino dung (Osbourn and Lanzotti 2009; Marneweck et al. 2017b). Acetophenone is a ketone, a VOC also highlighted as important in beaver (Castor canadensis) castoreum scent-marks (Müller-Schwarze and Houlihan 1991). This suggests that the dispersal of dung allows for the release of a VOC important for indicating male territorial status, which is otherwise dominated by plant odours when the bolus is intact.

The dispersal of dung increases the surface area, which consequently increases the area available for the emission of VOCs. The VOCs available for emission are limited as, unlike plants, scent marks do not produce VOCs (Lerdau et al. 1997; Archie and Theis 2011). So, increased odour emission should lead to reduced longevity, which is what we found in our study. In the case of dispersed male white rhino dung, a greater number of VOCs were emitted earlier, followed by a greater overall depletion over the 48 hours, compared to the more stable/less dramatic release of VOCs from intact dung. Therefore, there seems to be a trade-off between the intensity of the signal and its duration. These results suggest that the kicking action associated with scent marking in territorial white rhinos is for OSA, but carries the cost of reduced signal longevity. However, the fact that all territorial males kick their dung suggests that the benefits of OSA outweigh the costs of reduced longevity. Moreover, behavioural adjustments by territorial white rhinos, such as timing when they defecate, may help counteract reduced signal longevity.

White rhino territories tend to be relatively small (on average $1.65 \mathrm{~km}^{2}$; Owen-Smith (1975)), which would suggest that regular re-marking of middens could be achieved over a short period of time. Owen-Smith (1975) supports this by reporting territorial males to defecate in each of their middens on average every second day. If this were the case, then the impact of reduced signal longevity could be minimised, and the probability of individuals visiting the midden and detecting the olfactory signals increased. However, more recent evidence indicates that territorial males only defecate in the same midden on average once every ten days (Marneweck et al. 2018). Compounded with this, white rhino dung odours only last for a couple of days (Marneweck et al. 2017b). Although signals change over time, they are still recognisable as territorial male odours (i.e. still different to non-territorial odours after 48 hours; Marneweck et al. (2017b)). Thus, it would seem that at any one midden within a male's territory, there are long periods where the territorial male's signal would be present, but very weak. As dung is a limited resource, the likely reason that territorial males are not increasing the frequency at which they remark middens is that they are already defecating at the maximum frequency permitted by their physiology. Moreover, it seems that males attempt to maximise the spatial distribution of their dung across the $>30$ middens they can have in their territories (Owen-Smith 1973) by limiting how much they deposit at any one midden (Marneweck et al. 2018).

One way that territorial males could increase the probability of their signals being detected by other rhinos is to defecate strategically, so that the amplified signal strength is highest when the majority 
of individuals visit the midden. This would increase detectability and counteract the issue of reduced signal duration. As a number of non-resident rhinos move through a male's territory every day, defecating in any midden prior to peak visitation times would increase the probability of detection by these individuals. Yet, due to the size of its territory and the limitation of dung production, some visiting rhinos are inevitability going to visit middens where the territorial male's dung odour is weak. However, if key individuals are present in a male's territory (e.g. oestrous females, rival males) then a territorial male could likely increase the defecation frequency in the middens in that portion of its territory. For example, Owen-Smith (1973) observed a territorial male remain within a small portion of its territory after a rival male had intruded. While remaining in this area, the territorial male increased the frequency with which it defecated in the middens along that territory boundary, such that it defecated in them every two days. Thus, by defecating prior to or during peak visitation times, the probability of detection by these key individuals is likely increased. In line with this, we found that territorial males did in fact defecate both before and during times of high visitation from other individuals. This suggests that territorial males cope with the reduced signal duration after their OSA by responding with a strategy to increase detectability.

Many species using dung as a scent marking source also perform over-marking strategies, with regard to both territorial defence and mate guarding (Brachares and Arcese 1999; Jordan et al. 2011; Vogt et al. 2014). With this in mind, it is possible that the function of dung kicking by territorial male white rhinos may be for both OSA and over-marking. However, with other individuals defecating mostly around the edge of the midden, and territorial males defecating exclusively in the centre (Marneweck et al. 2018), we suggest that this is unlikely behaviour for white rhinos.

The results of our study identify the purpose of dung kicking in territorial male white rhinos. Specifically, territorial males use both OSA and strategic placement of signals both temporally (utilising middens at specific times) as well as spatially (placement within a midden, Marneweck et al. (2018)). Ultimately, by kicking dung, males increase detection of their odours by other individuals visiting the middens by increasing signal strength. Moreover, these signals may also provide distinctive and unambiguous signals to both intimidate males (potential rivals) and show competitive ability to females (potential mates). Finally, our results provide insight into the possible function of scraping behaviours observed from other communally defecating ungulates, such as sable and suni.

\section{REFERENCES}

Alberts AC (1992) Constraints on the design of chemical communication systems in terrestrial vertebrates. Am Nat 139:S62-S89

Amirav A, Dagan S (1997) A direct sample introduction device for mass spectrometry studies and gas chromatorgraphy mass spectrometry anlyses. Eur J Mass Spectrom 3:105-111 
Andersen KF, Vulpius T (1999) Urinary volatile constituents of the lion, Panthera leo. Chemical senses 24:179-189

Archie EA, Theis KR (2011) Animal behaviour meets microbial ecology. Animal Behav 82:425-436

Archunan G, Rajagopal T (2013) Detection of estrus in Indian blackbuck: Behavioural, hormonal and urinary volatiles evaluation. General and comparative endocrinology 181:156-166

Asa CS (1993) Relative contributions of urine and anal-sac secretions in scent marks of large felids. Am Zool 33:167-172

Barja I, de Miguel FJ, Barcena F (2004) The importance of crossroads in faecal marking behaviour of the wolves (Canis lupus). Die Naturwissenschaften 91:489-492

Barja I, de Miguel FJ, Bárcena F (2005) Faecal marking behaviour of Iberian wolf in different zones of their territory. Folia Zool 54:21-29

Bartoń K (2013) MuMIn: Multi-model inference. R package version 1.9. 13. The Comprehensive R Archive Network (CRAN), Vienna, Austria

Bossert WH (1968) Temporal patterning in olfactory communication. J Theor Biol 18:157-170

Brachares JS, Arcese P (1999) Scent marking in a territorial African antelope: II. The economics of marking with faeces. Animal Behav 57:11-17

Burger BV, Viviers MZ, Bekker JPI, Le Roux M, Fish N, Fourie WB, Weibchen G (2008) Chemical characterization of territorial marking fluid of male Bengal tiger, Panthera tigris. Journal of chemical ecology 34:659-671

Burnham KP, Anderson DR (1998) Model selection and inference: a practical information-theoretic approach. Springer-Verlag, New York,

Cross HB, Zedrosser A, Nevin O, Rosell F (2014) Sex discrimination via anal gland secretion in a territorial monogamous mammal. Ethol 120:1044-1052

Elkinton JS, Cardé RT (1984) Odor dispersion. In: Bell WJ, Cardé RT (eds) Chemical ecology of insects. Springer US, Boston, MA, pp 73-91. doi:10.1007/978-1-4899-3368-3_3

Estes RD (1991) The behavior guide to African mammals. Univ California Press, Berkeley, USA 
Giotto N, Laurent A, Mohamed N, Prevot N, Gerard J-F (2008) Observations on the behaviour and ecology of a threatened and poorly known dwarf antelope: the beira (Dorcatragus megalotis). Eur J Wildlife Res 54:539-547

Gorman ML, Mills MGL (1984) Scent marking strategies in hyaenas (Mammalia). J Zool 202:535-547

Gosling LM, Roberts SC (2001) Scent-marking by male mammals: cheat-proof signals to competitors and mates. Adv Study Behav 30:169-217

Hayward MW, Hayward GJ (2010) Potential amplification of territorial advertisement markings by black-backed jackals (Canis mesomelas). Behaviour 147:979-992

Hillman-Smith AKK, Owen-Smith N, Anderson JL, Hall-Martin AJ, Selaladi JP (1986) Age estimation of the white rhinoceros (Ceratotherium simum). J Zool 210:355-379

Jordan NR, Manser MB, Mwanguhya F, Kyabulima S, Rüedi P, Cant MA (2011) Scent marking in wild banded mongooses : 1. Sex-specific scents and overmarking. Animal Behav 81:31-42

Karthikeyan K, Muniasamy S, SankarGanesh D, Achiraman S, Archunan G (2013) Faecal chemical cues in water buffalo that facilitate estrus detection. Animal reproduction science 138:163-167

Lerdau M, Guenther A, Monson R (1997) Plant production and emission of volatile organic compounds. BioScience 47:373-383

Liaw A, Wiener M (2012) Classification and regression by randomForest. R News 2:18-22

Marneweck C, Jürgens A, Shrader AM (2017a) Dung odours signal sex, age, territorial and oestrous state in white rhinos. Proc R Soc B: Biol Sci 284:20162376

Marneweck C, Jürgens A, Shrader AM (2017b) Temporal variation of white rhino dung odours. Journal of chemical ecology 43:955-965

Marneweck C, Jürgens A, Shrader AM (2018) The role of middens in white rhino olfactory communication Animal Behav 140:7-18

Monfort A, Monfort N (1974) Notes sur l'écologie et le comportement des oribis (Ourebia ourebi, Zimmerman, 1783). Rev Ecol 28:169-208

Müller-Schwarze D, Houlihan PW (1991) Pheromonal activity of single castoreum constituents in beaver, Castor canadensis. Journal of chemical ecology 17:715-734 doi:10.1007/BF00994195 
Nimmermark S, Gustafsson G (2005) Influence of temperature, humidity and ventilation rate on the release of odor and ammonia in a floor housing system for laying hens. Agric Engineer Int 7:114

Oksanen J et al. (2015) vegan: community ecology package. R package version 22-1

Osbourn AE, Lanzotti V (2009) Plant-derived Natural Products: Synthesis, Function, and Application. Springer New York,

Owen-Smith N (1971) Territoriality in the white rhinoceros (Ceratotherium simum) Burchell. Nature 231:294-296

Owen-Smith N (1973) The behavioural ecology of the white rhinoceros. The University of Wisconsin

Owen-Smith N (1975) The social ethology of the white rhinoceros Ceratotherium simum (Burchell 1817). Z Tierpsychologie 38:337-384

Piñeiro A, Barja I (2012) The plant physical features selected by wildcats as signal posts: an economic approach to fecal marking. Die Naturwissenschaften 99:801-809

Pinheiro J, Bates D, DebRoy S, Sarkar D, Team RC (2015) nlme: linear and nonlinear mixed effects model.

Rachlow JL, Berkeley EV (1998) Correlates of male mating strategies in white rhinos (Ceratotherium simum). J Mammal 79 doi:10.2307/1383023

Sharpe LL (2015) Handstand scent marking: height matters to dwarf mongooses. Animal Behav 105:173-179

Skinner JD, Chimimba CT (2005) The Mammals of the Southern African Sub-region. Cambridge University Press, Cambridge, UK

Somers M, Rasa OAE, Apps PJ (1990) Marking behaviour and dominance in suni antelpe (Neotragus moschatus). Z Säugetierk 55:340-352

Stoddart DM (1976) Mammalian odours and pheromones. Edward Arnold Ltd, London, UK

Team RC (2016) A language and environment for statistical computing. R Foundation for Statistical Computing, Vienna

Theis KR, Schmidt TM, Holekamp KE (2012) Evidence for a bacterial mechanism for group-specific social odors among hyenas. Scientific reports 2:615 
Tinley KL (1969) Dikdik Madoqua kirki in South West Africa: Notes on distribution, ecology and behaviour. Madoqua 1:7-33

Vogt K, Zimmermann F, Kolliker M, Breitenmoser U (2014) Scent-marking behaviour and social dynamics in a wild population of Eurasian lynx Lynx lynx. Behavioural processes 106:98-106

Walther FR (1990) Duikers and dwarf antelopes. In: Parker SP (ed) Grzimek's encyclopedia of mammals, vol 5. McGraw-Hill, New York, pp 325-343

White AM, Swaisgood RR, Zhang H (2002) The highs and lows of chemical communication in giant pandas (Ailuropoda melanoleuca): effect of scent deposition height on signal discrimination. Behav Ecol Sociobiol 51:519-529

Zielinski WJ, Vandenbergh JG (1993) Testosterone and competitive ability in male house mice, Mus musculus: laboratory and field studies. Animal Behav 45:873-891 


\section{Supplementary material}

Table S1. Identified volatile organic compounds distinguished from non-territorial male white rhino dung odour (intact and dispersed). Compound identification criteria and notes: $\mathrm{a}=$ comparison of MS with published data; $\mathrm{b}=$ comparison of MS and retention time with published data; $\mathrm{c}=$ comparison of MS and retention time with authentic standard.

\begin{tabular}{|c|c|c|c|c|}
\hline Compound name & Functional group & Retention time & CAS \# & KOVATS index \\
\hline Acetic acid ${ }^{\mathrm{c}}$ & Hydrocarbon acid & 1.681 & $64-19-7$ & 645 \\
\hline Propanoic acid ${ }^{\mathrm{b}}$ & Hydrocarbon acid & 2.514 & 79-09-4 & 710 \\
\hline Isobutyric acid ${ }^{b}$ & Hydrocarbon acid & 3.396 & $79-31-2$ & 765 \\
\hline Butyric acid ${ }^{b}$ & Hydrocarbon acid & 4.019 & $107-92-6$ & 789 \\
\hline 3-Methylbutyric acid & Hydrocarbon acid & 4.976 & $503-74-2$ & 848 \\
\hline 2-Methylbutyric acid ${ }^{\mathrm{b}}$ & Hydrocarbon acid & 5.397 & $116-53-0$ & 863 \\
\hline Pentanoic acid ${ }^{b}$ & Hydrocarbon acid & 5.800 & $109-52-4$ & 841 \\
\hline Butylacetic acid ${ }^{\mathrm{b}}$ & Hydrocarbon acid & 8.038 & $1070-83-3$ & 952 \\
\hline Hexadecanoic acid ${ }^{\mathrm{b}}$ & Hydrocarbon acid & 25.602 & $112-39-0$ & 1870 \\
\hline Octadecanoic acid ${ }^{\mathrm{b}}$ & Hydrocarbon acid & 28.380 & $57-11-4$ & 2171 \\
\hline Pentan-1-ol ${ }^{b}$ & Hydrocarbon alcohol & 3.665 & $71-41-0$ & 766 \\
\hline Hexan-1-ol ${ }^{\mathrm{b}}$ & Hydrocarbon alcohol & 5.637 & $111-27-3$ & 860 \\
\hline 3-Nonanol ${ }^{\mathrm{a}}$ & Hydrocarbon alcohol & 9.909 & $624-51-1$ & - \\
\hline Nonan-2-ol ${ }^{\mathrm{b}}$ & Hydrocarbon alcohol & 10.939 & $628-99-9$ & 1100 \\
\hline Pentanal $^{\mathrm{b}}$ & Hydrocarbon aldehyde & 2.645 & $110-62-3$ & 693 \\
\hline Hexanal $^{\mathrm{c}}$ & Hydrocarbon aldehyde & 4.234 & $66-25-1$ & 776 \\
\hline Heptanal $^{\mathrm{c}}$ & Hydrocarbon aldehyde & 6.256 & $111-71-7$ & 901 \\
\hline
\end{tabular}




\begin{tabular}{|c|c|c|c|c|}
\hline Octanal $^{\mathrm{c}}$ & Hydrocarbon aldehyde & 8.449 & $124-13-0$ & 1003 \\
\hline Nonanal $^{c}$ & Hydrocarbon aldehyde & 10.976 & $124-19-6$ & 1103 \\
\hline Decanal $^{\mathrm{c}}$ & Hydrocarbon aldehyde & 13.166 & $112-31-2$ & 1205 \\
\hline 3-Ethylhexane ${ }^{c}$ & Hydrocarbon alkane & 4.180 & $619-99-8$ & 772.9 \\
\hline 2,4-Dimethylheptane ${ }^{\mathrm{b}}$ & Hydrocarbon alkane & 4.649 & $2213-23-2$ & 820 \\
\hline 4-Methyloctane ${ }^{b}$ & Hydrocarbon alkane & 5.475 & $2216-34-4$ & 862.85 \\
\hline Nonane $^{c}$ & Hydrocarbon alkane & 6.411 & $111-84-2$ & 900 \\
\hline Decane $^{\mathrm{c}}$ & Hydrocarbon alkane & 8.658 & $124-18-5$ & 1000 \\
\hline 4-Methyldecane ${ }^{\mathrm{b}}$ & Hydrocarbon alkane & 9.004 & $2847-72-5$ & 1059 \\
\hline 6-Methyloctadecane ${ }^{\mathrm{a}}$ & Hydrocarbon alkane & 11.506 & $10544-96-4$ & - \\
\hline 2-Methylundecane ${ }^{b}$ & Hydrocarbon alkane & 12.194 & $7045-71-8$ & 1163 \\
\hline 2,3-Dimethyldecane ${ }^{\mathrm{a}}$ & Hydrocarbon alkane & 12.497 & $17312-44-6$ & - \\
\hline Dodecane $^{c}$ & Hydrocarbon alkane & 13.222 & $112-40-3$ & 1200 \\
\hline 2,6-Dimethylundecane ${ }^{\mathrm{b}}$ & Hydrocarbon alkane & 13.376 & $17301-23-4$ & 1213 \\
\hline 2-Methyldecane ${ }^{a}$ & Hydrocarbon alkane & 14.347 & $6975-98-0$ & - \\
\hline Tridecane $^{c}$ & Hydrocarbon alkane & 15.217 & $629-50-5$ & 1300 \\
\hline 2,6,10-Trimethyldodecane ${ }^{\mathrm{a}}$ & Hydrocarbon alkane & 18.233 & $3891-98-3$ & - \\
\hline Pentadecane $^{\mathrm{c}}$ & Hydrocarbon alkane & 18.935 & $629-62-9$ & - \\
\hline Hexadecane $^{\mathrm{c}}$ & Hydrocarbon alkane & 20.636 & $544-76-3$ & - \\
\hline Heptadecane $^{c}$ & Hydrocarbon alkane & 22.288 & $629-78-7$ & - \\
\hline
\end{tabular}



Octadecane $^{\mathrm{c}}$
(E)-Oct-2-ene ${ }^{b}$
(Z)-Oct-2-ene ${ }^{\text {b }}$
(3E)-3-Nonene ${ }^{\mathrm{a}}$
(3E)-3-Decene

Undec-1-ene ${ }^{\mathrm{a}}$

(3Z)-3-Dodecene ${ }^{a}$

Tridecene- $1^{\mathrm{b}}$

Pentan-2-one

Hexan-2-one ${ }^{b}$

5-Methylhexan-2-one ${ }^{a}$

Acetophenone $^{c}$

Undecan-2-one ${ }^{\mathrm{b}}$

Dodecan-2-one

Toluene ${ }^{\mathrm{c}}$

alpha-Methyltoluene ${ }^{\mathrm{b}}$

1,4-Dimethyl benzene ${ }^{c}$

Styrene $^{c}$

Benzaldehyde ${ }^{c}$

p-Cresol ${ }^{\mathrm{c}}$

m-Cresol ${ }^{\mathrm{c}}$

1-Isopropenyl-2-methylbenzene ${ }^{a}$

\begin{tabular}{|c|c|c|c|}
\hline Hydrocarbon alkane & 23.858 & $593-45-3$ & - \\
\hline Hydrocarbon alkene & 4.319 & $111-67-1$ & 810 \\
\hline Hydrocarbon alkene & 4.379 & $7642-04-8$ & 815 \\
\hline Hydrocarbon alkene & 6.228 & $20063-77-8$ & - \\
\hline Hydrocarbon alkene & 7.773 & $19150-21-1$ & - \\
\hline Hydrocarbon alkene & 10.734 & $821-95-4$ & - \\
\hline Hydrocarbon alkene & 13.055 & $7239-23-8$ & - \\
\hline Hydrocarbon alkene & 15.060 & $2437-56-1$ & 1291 \\
\hline Hydrocarbon ketone & 2.432 & $107-87-9$ & 690 \\
\hline Hydrocarbon ketone & 4.029 & $591-78-6$ & $7-90$ \\
\hline Hydrocarbon ketone & 5.991 & $110-12-3$ & \\
\hline Hydrocarbon ketone & 10.137 & $98-86-2$ & 1062 \\
\hline Hydrocarbon ketone & 14.953 & $112-12-9$ & 1292 \\
\hline Hydrocarbon ketone & 14.608 & $6175-49-1$ & - \\
\hline Benzenoid & 3.726 & $108-88-3$ & 762 \\
\hline Benzenoid & 5.561 & $100-41-4$ & 855 \\
\hline Benzenoid & 5.696 & $106-42-3$ & 862 \\
\hline Benzenoid & 6.224 & $100-42-5$ & 895 \\
\hline Benzenoid & 7.769 & $100-52-7$ & 947 \\
\hline Benzenoid & 10.717 & $106-44-5$ & 1077 \\
\hline Benzenoid & 10.525 & $108-39-4$ & - \\
\hline Benzenoid & 10.492 & $7399-49-7$ & - \\
\hline
\end{tabular}


(3E)-2,6-Dimethyl-1,3,7-octatriene ${ }^{\mathrm{a}}$

1-Methyl-3-\{2-methyl-2-propenyl)cyclopentane ${ }^{a}$

6-Methyl-5-heptene-2-one ${ }^{\mathrm{b}}$

(6E)-2,6-Dimethyl-2,6-octadiene ${ }^{\mathrm{b}}$

(6Z)-2,6-Dimethyl-2,6-octadiene ${ }^{\mathrm{a}}$

(3E)-3-Ethyl-2,5-dimethyl-1,3-hexadiene ${ }^{\text {a }}$

2-Ethylhexan-1-ol ${ }^{\mathrm{a}}$

(3-Methylbutylidene)cyclopentane ${ }^{\mathrm{a}}$

(5E)-4-Methyl-1,5-heptadiene ${ }^{\mathrm{a}}$

(6E)-2,6-Dimethyl-2,6-octadiene ${ }^{\mathrm{b}}$

alpha-lonene ${ }^{\text {a }}$

Quinoline $^{\mathrm{a}}$

Bicyclo[10.1.0]tridec-1-ene ${ }^{\mathrm{a}}$

1,5,9-Undecatriene, 2,6,10-trimethyl- ${ }^{\mathrm{a}}$

(5E)-6,10-Dimethyl-5,9-undecadien-2-one ${ }^{\mathrm{a}}$

(6E)-3,7,11-Trimethyl-1,6,10-dodecatrien-3-ol a

3,7,11-Trimethyl-1-dodecanol ${ }^{\mathrm{a}}$

6,10,14-Trimethyl-2-pentadecanone ${ }^{\mathrm{a}}$

(2E)-3,7,11,15-Tetramethyl-2-hexadecene ${ }^{\text {b }}$

1,2-Benzenedicarboxylic acid, dibutyl ester ${ }^{\mathrm{b}}$

1,7,7-Trimethyltricyclo[2.2.1.0,2,6]heptane ${ }^{\mathrm{a}}$

2,7-Dimethyl-1,7-octadiene ${ }^{\mathrm{a}}$

alpha-Pinene $^{c}$

$\begin{array}{llll}\text { Miscellaneous } & 7.898 & 6876-07-9 & - \\ \text { Miscellaneous } & 8.113 & 75873-00-6 & - \\ \text { Miscellaneous } & 8.232 & 110-93-0 & 984 \\ \text { Miscellaneous } & 8.332 & 2609-23-6 & 1004 \\ \text { Miscellaneous } & 8.636 & 2492-22-0 & - \\ \text { Miscellaneous } & 8.922 & 62338-07-2 & - \\ \text { Miscellaneous } & 9.060 & 104-76-7 & - \\ \text { Miscellaneous } & 9.253 & 53366-51-1 & - \\ \text { Miscellaneous } & 9.813 & 998-94-7 & - \\ \text { Miscellaneous } & 9.780 & 2792-39-4 & 990 \\ \text { Miscellaneous } & 13.468 & 475-03-6 & - \\ \text { Miscellaneous } & 13.984 & 91-22-5 & - \\ \text { Miscellaneous } & 17.092 & 54766-91-5 & - \\ \text { Miscellaneous } & 17.161 & 62951-96-6 & - \\ \text { Miscellaneous } & 17.959 & 3796-70-1 & 1445 \\ \text { Miscellaneous } & 19.597 & 7212-44-4 & 1561 \\ \text { Miscellaneous } & 23.169 & 6750-34-1 & - \\ \text { Miscellaneous } & 24.441 & 502-69-2 & 1848 \\ \text { Miscellaneous } & 24.487 & 14237-73-1 & - \\ \text { Miscellaneous } & 25.569 & 84-74-2 & 1897 \\ \text { Monoterpene } & 6.983 & 508-32-7 & 924 \\ \text { Monoterpene } & 7.069 & 59840-10-7 & - \\ \text { Monoterpene } & 7.264 & 80-56-8 & 932\end{array}$


3,7-Dimethyl-1,6-octadiene $(\mathrm{S})^{\mathrm{a}}$

3,7-Dimethyl-1,6-octadiene $(\mathrm{R})^{\mathrm{a}}$

Camphene $^{\mathrm{b}}$

beta-Pinene ${ }^{c}$

alpha-Terpinolene

2-Carene ${ }^{\mathrm{a}}$

alpha-Terpine

Cymene $^{\mathrm{a}}$

Limonene $^{c}$

gamma-Terpinen $^{\mathrm{a}}$

Geranial $^{\mathrm{a}}$

Linalool $^{\mathrm{c}}$

p-Mentha-1,4(8)-diene ${ }^{\mathrm{a}}$

3-Methyl-1H-indole ${ }^{c}$

Farnesane $^{\mathrm{a}}$

(+)-Cyclosativene ${ }^{\mathrm{a}}$

alpha-Copaene ${ }^{\mathrm{a}}$

alpha-Bourbonene ${ }^{\mathrm{a}}$

beta-Elemene

4,11,11-Trimethyl-8-methylenebicyclo[7.2.0]undec-4-ene ${ }^{\mathrm{a}}$

beta-Caryophyllene ${ }^{\mathrm{c}}$

beta-Gurjunene ${ }^{a}$

alpha-Caryophyllene ${ }^{\mathrm{a}}$
Monoterpene

Monoterpene

Monoterpene

Monoterpene

Monoterpene

Monoterpene

Monoterpene

Monoterpene

Monoterpene

Monoterpene

Monoterpene

Monoterpene

Monoterpene

Nitrogen compound

Sesquiterpene

Sesquiterpene

Sesquiterpene

Sesquiterpene

Sesquiterpene

Sesquiterpene

Sesquiterpene

Sesquiterpene

Sesquiterpene
7.395

7.541

7.615

8.275

8.722

8.764

9.110

9.257

9.405

10.031

10.371

10.637

10.668

16.846

16.666

16.733

16.817

16.997

17.074

17.431

17.715

17.914

18.357
10281-55-7 -

2436-90-0 -

79-92-5 946

127-91-3 980

586-62-9

554-61-0

99-86-5

527-84-4

1461-27-4 1039

99-85-4 -

141-27-5 -

78-70-6 1096

586-62-9 -

83-34-1

3891-98-3

22469-52-9 -

3856-25-5 1392

-

515-13-9

118-65-0 1413

87-44-5 1440

17334-55-3 1427.7

6753-98-6 1459 
delta-Cadinene

alpha-Panasinsen ${ }^{\mathrm{a}}$

alpha-Calacorene ${ }^{\mathrm{a}}$
Sesquiterpene

Sesquiterpene

Sesquiterpene
19.400

19.495

19.814
483-76-1

56633-28-4

21391-99-1 